\title{
Relations between private practice and the NHS: a personal view
}

\author{
DAVID E BOLT
}

I have been chairman of the Joint Consultants Committee/ Central Committee for Hospital Medical Services Independent Practice Subcommittee for six years. But, as I have now retired from the National Health Service and private practice, I handed over this role to $\mathrm{Mr}$ John Chawner last month. I feel strongly about the importance and legitimacy of private practice in this country and think that this is an opportune moment to record my views on the subject.

Some people believe that in a country with a national health service private practice should not exist. If honestly held this view must command respect. Unfortunately, at least some of those who hold such a view will not concede that there is an alternative view that deserves consideration. I believe that the continuation of private practice may be justified on three counts.

Firstly, choice is essential in a free society. Economic considerations may preclude such a choice for many citizens, but that is a criticism of the financial structure of society rather than an argument against the existence of choice. Apart from the very poor, many people who elect to use the NHS have the means to use the private service but prefer to spend their money on consumer durables or foreign holidays. This is entirely a matter for them: they are merely exercising their fundamental right to freedom of choice.

Secondly, it is essential for staff and patients of the NHS that it should not be a monopoly provider of health care. For the staff-especially those whose professions are exclusively applicable to the care of patients-there must be alternative ways for them to earn a living. There must be a market place where an independent valuation may be put on their services, lest they find themselves tied inescapably to an unjust level of remuneration. Indeed, it may be argued that the recent problems relating to the pay of non-medical staff in the NHS, particularly nurses, arose because the NHS is a near monopoly. If the balance between the NHS and private practice was more equal market forces would protect incomes more efficiently than a review body ever could. For patients, the existence of an alternative to the NHS provides a vital comparison against which the standards of NHS care may be judged. It is, of course, equally true the other way round. The NHS provides extremely well for emergency patients and those who are gravely ill and this is a great challenge for the private sector. On the other hand, the private sector provides extremely well for the more routine problems and must always be consumer oriented to a greater degree than the NHS. This competition is advantageous to NHS and private patients. I would not like to see it replaced by a monopoly in health care.

Thirdly, British patients who seek private health care have paid their full share in the cost of the NHS. If, either by direct payment or by subscription to a provident association, they pay again for private service they are increasing the total pool of resources for the provision of health care and leaving much needed time and facilities in the NHS for others. It might be supposed that they would be particularly welcome in NHS hospitals on such terms but, sadly, this is often not the case. I see great merits in this arrangement, compared with a system that

Hampton Hill, Middlesex TW12 1HP

DAVID E BOLT, MB, FRCS, retired consultant surgeon

allows rebate of health contributions to those seeking other methods of insurance. It provides a clear protection against the accusation that the NHS subsidises the cost of private health $\frac{\bar{\sigma}}{\vec{D}}$ care.

\section{Consultants in the private sector}

I have been primarily concerned with consultants. The over- $\frac{\partial}{3}$ whelming majority of them believe deeply in the underlying principles of the NHS and, if occasionally critical of the details of $\infty$ how those principles are carried out, they wish to see the NHS a strong and effective force in patient care. Consultants in private $\mathscr{O}$ practice are not happy to see patients who are seeking private

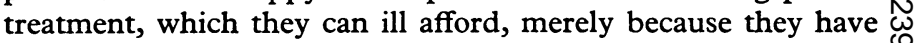
failed to get the necessary treatment through the NHS. The welcome private patient is one who has freely chosen that path with the resources-be they personal or through insurance- $\vec{v}$ that relieve him of anxiety about the financial consequences. The consultant in the NHS may freely exercise his clinical function but, even so, is constrained by the rigidity of the system and $\stackrel{\equiv}{2}$ the availability of resources. With private care he is able to conduct his work in the way he chooses. This feeling of pro- $\mathscr{\infty}_{\infty}$ fessional freedom has, I am sure, more to do with the enthusiasm $\omega$ of consultants for private practice than has the financial reward. ㄱ Some people think that private practice is a licence to print money. In my experience it is a licence to work hard with rewards that are more than merely financial.

\section{Relations with the NHS}

One of the criticisms most often levelled at private practice is that consultants who practise privately abuse the NHS. It is said that they give greater priority to patients seen in private than is clinically justified, that they put investigational work for private outpatients through the NHS without payments being made, that they use NHS equipment or facilities without permission or 0 payment, and that they carry on private practice to an extent incompatible with their contractual obligations to the Health $\frac{\text { o }}{2}$ Service. I believe that the incidence of such abuses is small but $\mathrm{N}$ any examples are publicised and damage the image of private $D$ practice far in excess of the importance of the incident. Nevertheless, in the context of private practice, consultants must seek to imitate Caesar's wife. We cannot afford such stories if private practice is to continue to receive the public support it now does. Moreover, some of these practices are dishonest, exposing the perpetrator to the risk of the courts and of the Professional $\stackrel{0}{\subset}$ Conduct Committee of the General Medical Council. In addition, health authorities cannot be expected to look sympatheti- + cally on private practice if they are denied their legitimate share in the earnings, particularly at a time when they are facing $\underset{\mathbb{D}}{\mathbb{D}}$ financial difficulties. It is essential that private outpatients are $\frac{\rho}{\oplus}$ clearly identified so that appropriate charges may be made on $\cong$ behalf of the authority. Moreover, it is hardly fair to colleagues who are contributing to the investigation of private patients if $\delta$ they are denied the opportunity to make legitimate charges for 


\section{New agreement for police surgeons and other local authority work}

As the $B M F$ goes to press details are emerging of an agreement between the BMA and representatives of the local authorities. The agreement introduces-retrospectively from 1 July 1982-a new contract for police surgeons. There is to be an increase in the availability fee (retainer) paid to all police surgeons to offset, firstly, the expected loss in income from forthcoming changes in the breathalyser law, and, secondly, the fact that in future second and subsequent examinations conducted at one police station in the course of a single visit will be paid at a lower level than initial examinations.

Police surgeons already in post do, however have the option of remaining on their old contract, which has been further revised with effect from July 1982, but which will thereafter remain frozen.

BMA members may obtain full details from the secretary of the BMA by quoting their current membership number and the reference "Fees 92."

\section{Other local authority work}

Fees for medical referees at crematoria, part time occupational health work for local authorities, and coroners' analytical work are being increased with effect from April 1982. A revised milage allowance, covering police surgeons and all local authority work, is introduced with effect from 1 September 1982. Details of the fees for local authority work are

\section{Variable cost rents}

A new arrangement came into effect on 15 November 1982 for variable as opposed to fixed cost rents. Since 1 November 1982 the General Practice Finance Corporation has been offering general practitioners the option of borrowing at a variable interest rate as an alternative to the fixed rate. This change in the corporation's lending arrangements necessitated a review of the prescribed percentage used by family practitioner committees in determining a cost rent reimbursement to doctors.

The cost rent scheme reimburses doctors for the interest they would have to pay to finance the original cost of new purpose built premises or their equivalent. The reimbursement is made whether the general practitioner borrows the money or not. The percentage is fixed at the same rate as the corporation's lending rate. In future, repayments from the family practitioner committee to cover interest charges will be based on the corporation's variable rate of interest, except in some circumstances where the fixed rate will still apply. Anyone who is already on a fixed rate or has signed their contract or lease will stay on a fixed rate.

\section{Government will not "close" health care professions}

The government has decided not to introduce legislation on the use of professional titles in the professions supplementary to medicine and the speech therapy profession. A DHSS consultative document had suggested that there should be a general restriction on either the practice of, or the use of the title of, the profession to those who were qualified. The health care professions concerned are chiropo- dists, dietitians, medical laboratory scientific officers, occupational therapists, orthoptists, physiotherapists, radiographers, and remedial gymnasts. People who are not registered with the Council for the Professions Supplementary to Medicine are debarred from employment in the NHS but not elsewhere. Regulations prescribe conditions under which a speech therapist may be employed in the NHS. also available to members quoting the reference "Fees 71." Members are invited to enclose a stamped addressed envelope to expedite dispatch of the information.

\section{Strike action}

The provisional figure for the number of days lost in the first nine months of 1982 through industrial action in the United Kingdom was 3130000 . The figures for previous years since 1975 are given below.

\begin{tabular}{lrc}
\hline Year & No of staff & No of days lost \\
\hline 1975 & 6000 & 20000 \\
1976 & 4440 & 15000 \\
1977 & 2970 & 8200 \\
1978 & 3700 & 15000 \\
1979 & 39200 & 621000 \\
1980 & 14000 & 41000 \\
$1981 *$ & 16400 & 44000 \\
$1982^{*}$ & $600000 \dagger$ & $3130000 \dagger$ \\
\hline *Nine months. & & \\
+Provisional. & &
\end{tabular}

\section{New milage allowances}

Revised milage allowances have been agreed with effect from 1 November 1982. Rates for doctors in community medicine are negotiated through the General Whitley Council and are set out in Advance Letter (GC) 8/82. Rates for hospital doctors are identical to the Whitley Council rates and are set out in Advance Letter (MD) $7 / 82$.

Regular user rates

\begin{tabular}{lccc}
\hline Engine capacity & Lump sum & $\begin{array}{c}\text { Up to } 9000 \\
\text { miles }\end{array}$ & Thereafter \\
\hline 501 to $1000 \mathrm{cc}$ & $£ 311$ & $15 \cdot 6 \mathrm{p}$ & $8 \cdot 7 \mathrm{p}$ \\
1001 to $1500 \mathrm{cc}$ & $£ 376$ & $18 \cdot 0 \mathrm{p}$ & $9 \cdot 6 \mathrm{p}$ \\
1501 to $2000 \mathrm{cc}$ & $£ 464$ & $21 \cdot 3 \mathrm{p}$ & $10 \cdot 9 \mathrm{p}$ \\
Over $2000 \mathrm{cc}$ & $£ 464$ & $23 \cdot 9 \mathrm{p}$ & $13 \cdot 6 \mathrm{p}$
\end{tabular}

Standard rates

\begin{tabular}{lccc}
\hline Engine capacity & $\begin{array}{c}\text { Up to } 3500 \\
\text { miles }\end{array}$ & $\begin{array}{c}3501 \text { to } \\
9000 \text { miles }\end{array}$ & Thereafter \\
\hline 501 to $1000 \mathrm{cc}$ & $21 \cdot 2 \mathrm{p}$ & $17 \cdot 8 \mathrm{p}$ & $8 \cdot 7 \mathrm{p}$ \\
1001 to $1500 \mathrm{cc}$ & $24 \cdot 7 \mathrm{p}$ & $20 \cdot 6 \mathrm{p}$ & $9 \cdot 6 \mathrm{p}$ \\
1501 to $2000 \mathrm{cc}$ & $29 \cdot 5 \mathrm{p}$ & $24 \cdot 5 \mathrm{p}$ & $10.9 \mathrm{p}$ \\
Over $2000 \mathrm{cc}$ & $32 \cdot 1 \mathrm{p}$ & $27 \cdot 1 \mathrm{p}$ & $13 \cdot 6 \mathrm{p}$
\end{tabular}

Relations between private practice and the NHS-continued from page 239

their services. The occasional patient, seen in private, who cannot afford further private investigation or treatment, may be catered for through the normal NHS machinery.

\section{Geographical whole time principle}

Private inpatient care is increasingly provided on non-NHS premises. This is almost certainly inevitable for political reasons and I have frequently urged my colleagues to make such provision while there is still time. Even so, I have always believed in the geographical whole time principle, which minimises the amount of professional time lost in car travel and, no less importantly, reduces the length of the professional day and the strain that it entails by concentrating all the consultant's work in one place. The fact that whenever an emergency arises, whether among NHS or private patients, consultant skills are immediately available is an enormous benefit to both groups of patients, and it is sad that the reason that this ideal arrangement cannot continue to exist is political prejudice. If some future government takes steps to eliminate all private work from NHS premises the sufferers will be the NHS patients. There are areas of the country where the provision of alternative premises for private work will always be financially impossible and specialties where the capital costs of equipment may only be justified by intensive use. Recruitment of first class consultant staff to such places and specialties will become more difficult, whatever financial inducement the NHS may be able to offer. It is probably too much to hope that, in the fullness of time, sufficient agreement on the place of private practice in the provision of health care might emerge to allow a common policy on the subject between all political parties. The provision of satisfactory health care for all is more important than political attitudes.

.

